\title{
Long-Lived Excited Electronic States of the Dichloroethylene Cation Isomers Probed by Charge Exchange Ionization
}

\author{
Mijin Kim, Joong Chul Choe, ${ }^{*}$ and Myung Soo Kim \\ National Creative Research Initiative Center for Control of Reaction Dynamics and School of Chemistry, \\ Seoul National University, Seoul, South Korea
}

Charge exchange technique has been used to detect the presence of long-lived excited electronic states of trans-, cis-, and 1,1- $\mathrm{C}_{2} \mathrm{H}_{2} \mathrm{Cl}_{2}^{+*}$. The $\tilde{\mathrm{B}}$ states of the three cations which are formed by removal of an electron from an in-plane chlorine nonbonding orbital of the corresponding neutrals have been found to have long lifetimes (tens of microseconds or longer). Whether the $\tilde{A}$ states formed by removal of an electron from the other in-plane chlorine nonbonding orbitals are long-lived also can not be determined by the present experiments. Cations in the excited electronic states above the $\tilde{\mathrm{B}}$ states were not detected because of their prompt dissociation following intramolecular relaxation or radiative decay. (J Am Soc Mass Spectrom 2004, 15, 1266-1273) (c) 2004 American Society for Mass Spectrometry

$\mathrm{I}$ nvestigation of the properties of excited electronic states is one of the frontier research subjects in chemistry, physics, and related fields [1-4]. For example, accurate calculation of excited state properties is one of the major research efforts in the field of quantum chemistry. Reactions occurring in excited electronic states have also been investigated. Dynamics of polyatomic cations in excited electronic states have special relevance to the field of mass spectrometry because the theory of mass spectra hypothesizes very rapid internal conversion from excited electronic states to the ground electronic state in such systems [5]; that is to say, dissociation of a polyatomic cation is assumed to occur in the ground electronic state. Even though many exceptions to the above hypothesis were observed [6-15], most were due to rapid dissociation in repulsive excited states, prior to internal conversion [6-9]. Examples of very slow internal conversion $[10,11]$, or cases of very long-lived excited electronic states [12-21], were rare especially for polyatomic cations consisting of more than three atoms.

The first encounter with a very long-lived excited electronic state in this laboratory occurred in the photodissociation study of the benzene cation [22], which showed that its $\tilde{\mathrm{A}}^{2} \mathrm{E}_{2 \mathrm{~g}}$ state (often called $\tilde{\mathrm{B}}^{2} \mathrm{E}_{2 \mathrm{~g}}$ state) was

Published online July 17, 2004

Address reprint requests to Dr. M. S. Kim, National Creative Research Initiative Center for Control of Reaction Dynamics and School of Chemistry, Seoul National University, Seoul 151-742, South Korea. E-mail: myungsoo@plaza.snu.ac.kr

*Permanent address: Department of Chemistry, University of Suwon, Suwon 440-600, Republic of Korea. present $30 \mu \mathrm{s}$ after formation. Then, a more direct method based on the detection of charge exchange signal, $\mathrm{B}^{+}$, from a reagent (B) in a separate collision cell was developed to find the presence of a polyatomic cation $\left(\mathrm{A}^{+}\right)$in an excited electronic state [23].

$$
\begin{aligned}
& \mathrm{A}^{+}+\mathrm{B} \rightarrow \mathrm{A}+\mathrm{B}^{+}, \Delta \mathrm{E} \\
& \Delta \mathrm{E}=\mathrm{IE}(\mathrm{B})-\mathrm{RE}\left(\mathrm{A}^{+}\right)
\end{aligned}
$$

Here IE is the ionization energy of $B$ and $R E$ is the recombination energy of $\mathrm{A}^{+}$. When the laboratory translational energy of $\mathrm{A}^{+}$was kept at $100 \mathrm{eV}$ or lower and the pressure of $B$ inside the collision cell was adjusted such that the intensity of $\mathrm{A}^{+}$was attenuated by $\sim 20 \%, B^{+}$with the intensity as large as a few percent of $\mathrm{A}^{+}$was observed when the reaction was exoergic or resonant. The $\mathrm{B}^{+}$intensity was significant until the reaction was endoergic by $0.1 \mathrm{eV}$ [24], beyond which it decreased rapidly, by orders of magnitude. This exoergicity rule was utilized to determine $\mathrm{RE}$ of $\mathrm{A}^{+}$and hence the highest electronic state surviving several microseconds after the ion formation; that is to say, charge exchange gases with different IEs were used and $\mathrm{RE}$ of $\mathrm{A}^{+}$was estimated from the presence/absence of the prominent $\mathrm{B}^{+}$signal.

In our initial search for the long-lived excited electronic states of polyatomic cations, those displaying well-resolved vibrational structures in the photoelectron spectra were the prime candidates. Accordingly, the $\tilde{\mathrm{B}}^{2} \mathrm{~B}_{2}$ states of chlorobenzene, bromobenzene, ben- 


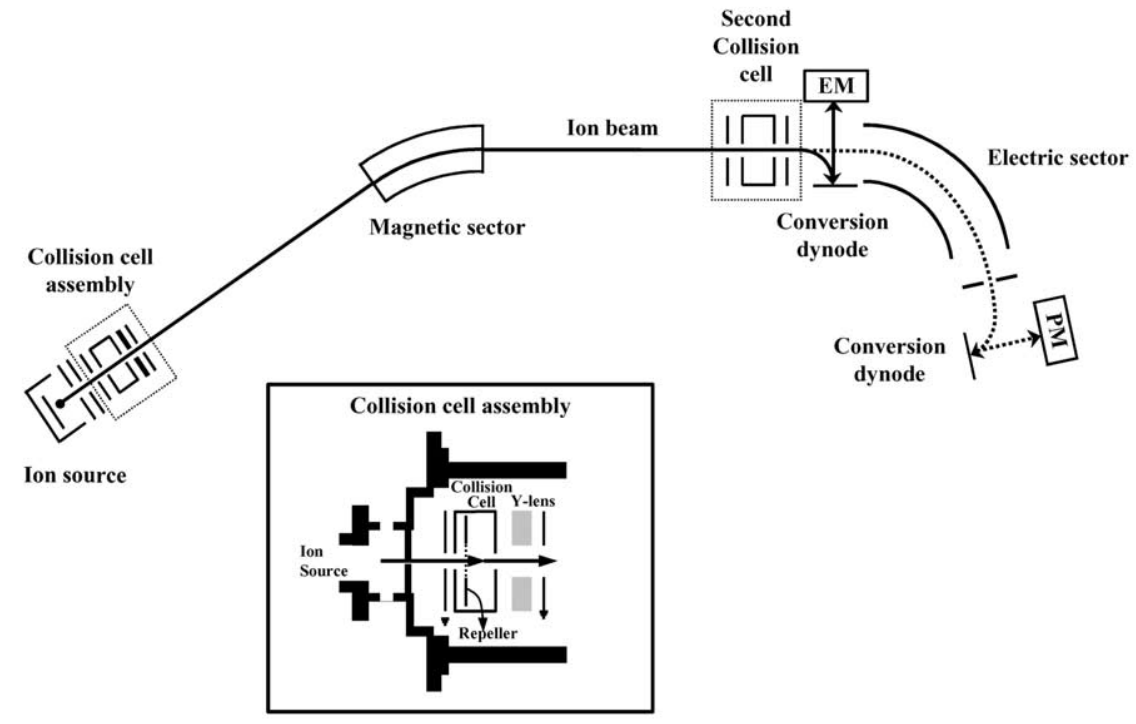

Figure 1. Diagram of the double focusing mass spectrometer with reversed geometry (VG Analytical ZAB-E). The inset shows details of the first charge exchange cell.

zonitrile, and phenylacetylene cations were found to be long-lived [25]. Similarly, the $\tilde{A}^{2} \mathrm{~A}^{\prime}$ states of vinylchloride, vinylbromide, vinyliodide, acrylonitrile cations were found to be long-lived [26]. A feature common to all these states is that they are generated by removal of an electron from an in-plane orbital, in-plane nonbonding $\mathrm{p}$ orbitals of halogens or in-plane $\pi$ orbitals of triple bonds. In contrast, the ground states of these cations are generated by removal of an electron from the $\pi$ systems which are perpendicular to the molecular plane.

Planar molecules with multiple halogen substitution have more than one in-plane nonbonding orbital and it would be interesting to see if the above correlation would also hold for such systems. Three isomers of dichloroethylene cations, trans, cis, and 1,1, have been investigated and are reported in this paper.

\section{Experimental}

1,1-, cis-1,2-, and trans-1,2-dichloroethylenes were purchased from TCI (Tokyo, Japan). Fluoromethane was purchased from Lancaster (Lancashire, UK) and other chemicals from Sigma (Milwaukee, WI). All the chemicals were of the highest purity commercially available and were used without further purification.

A diagram of the double focusing mass spectrometer with reversed geometry VG ZAB-E (Manchester, UK) is shown in Figure 1. The first collision cell located between the ion source and the magnetic sector was modified to optimize the detection of ions generated from the reagent gas inside the cell by charge exchange. Details of the modifications made were reported previously [23]. Sample was introduced to the ion source at $140{ }^{\circ} \mathrm{C}$ via a glass capillary connected to a reservoir ("septum inlet") and ionized under the electron ionization (EI) condition at $17 \mathrm{eV}$ electron energy. Ions were accelerated with high voltage $\left(\mathrm{V}_{\mathrm{S}}\right)$ of $4 \mathrm{kV}$. Experimental conditions for the charge exchange in the first and second cells are the same. In each case, the cell was floated at high voltage, $\mathrm{V}_{\mathrm{C}}$ and $\mathrm{V}_{\mathrm{C}}{ }^{\prime}$, respectively, such that the incoming ion had the translational energy of 50 $\sim 100 \mathrm{eV}$ inside the cell. Reagent gas pressure was adjusted to attenuate the incoming ion beam by $\sim 20 \%$, which was the upper limit of the single collision condition [27].

\section{Methods of Reagent Ion Detection}

Methods to identify ions generated from a reagent gas using a double focusing mass spectrometer with reverse geometry were developed previously [23, 25]. A brief account is as follows. Three types (I, II, and III) of ions exit the first collision cell, which can be differentiated by their translational energies, $\mathrm{K}_{\mathrm{I}}, \mathrm{K}_{\mathrm{II}}$, and $\mathrm{K}_{\mathrm{III}}$ [28].

$$
\begin{aligned}
& \text { Type I, } \mathrm{K}_{\mathrm{I}}=\mathrm{eVs} \\
& \text { Type II, } \mathrm{K}_{\mathrm{II}}=\mathrm{e}\left[\mathrm{V}_{\mathrm{C}}+\left(m_{2} / m_{1}\right)\left(\mathrm{V}_{\mathrm{S}}-\mathrm{V}_{\mathrm{C}}\right)\right] \\
& \text { Type II, } \mathrm{K}_{\mathrm{III}}=\mathrm{eV}_{\mathrm{C}}
\end{aligned}
$$

These are ions generated in the ion source (Type I), their collision-induced dissociation products generated inside the cell (Type II), and ions generated from the reagent gas inside the cell (Type III). The effective $m / z$ of each ion in single focusing mass spectrometry can be calculated with

$$
m / z=\mathrm{B}^{2} \mathrm{r}^{2} \mathrm{e}^{2} / 2 \mathrm{~K}
$$

Here, $r$ is the magnet radius, $B$ is the magnetic field, and 
$\mathrm{K}$ is the translational energy, one of $\mathrm{K}_{\mathrm{I}} \sim \mathrm{K}_{\mathrm{III}}$. Since the electric sector is an energy analyzer, only ions of a particular type can be detected by setting the electric sector potential to transmit ions with the corresponding translational energy. To detect only the Type III ions, we set the electric sector potential to transmit ions with the translational energy $\mathrm{eV}_{\mathrm{C}}$ even though the acceleration potential $\mathrm{V}_{\mathrm{S}}$ is applied in the ion source. Then, the spectrum is recorded with the usual double focusing mode, namely by scanning the magnetic field and detecting ions with a detector located after the electric sector. This will be called $\mathrm{eV}_{\mathrm{C}}$ double focusing mass spectrometry. Since the translational energies of Types I and II ions are different from $\mathrm{eV}_{C}$, only Type III ions will be detected in the $\mathrm{eV}_{C}$ double focusing mode. The second scheme is to detect reagent gas ions generated inside the second cell using mass-analyzed ion kinetic energy spectrometry (MIKES) [29]; that is to say, the magnetic sector field is set to transmit the molecular ions generated inside the ion source and the electric sector potential is scanned. The ions generated from the reagent gas inside the second cell appear in the MIKE spectrum at the translational energy $\mathrm{eV}_{\mathrm{C}}{ }^{\prime}$. Identification of charge exchange processes is not as definitive as in the first cell experiments because $\mathrm{m} / \mathrm{z}$ of the ions generated can not be determined in this scheme. The main utility of this scheme is to confirm that the molecular ion, not the fragment ions, generated in the source by EI is responsible for the charge exchange ionization occurring in the collision cells. Spectra were recorded using the two schemes in all the charge exchange investigations because the information obtained is complementary.

\section{Results and Discussion}

There are a few technical difficulties that can interfere with the present measurements. The first is the leakage of the reagent gas from the first cell to the ion source. The reagent gas ion, $\mathrm{B}^{+}$, generated in the ion source by $\mathrm{EI}$ is Type I and can be distinguished from the same ion generated in the cell (Type III). However, excessive generation of the Type $\mathrm{I} \mathrm{B}^{+}$would lead to substantial Type III $\mathrm{B}^{+}$through symmetric charge exchange, $\mathrm{B}^{+}+$ $\mathrm{B} \rightarrow \mathrm{B}+\mathrm{B}^{+}$. As described in previous papers [23, 25], the first cell was designed to reduce the reagent gas leakage as much as possible. As shown in the inset of Figure 1, an additional slit was installed between the ion source chamber and the collision cell assembly evacuated by analyzer pumping system for this purpose. In the actual measurements, care was taken such that the Type I B ${ }^{+}$intensity was comparable to or less than the Type III intensity. The same slit restricted the gas leakage from the source to the first collision cell, so that we could hardly detect the Type III $\mathrm{A}^{+}$ions. The second difficulty arises from the fact that not only the molecular ion but some fragment ions are also generated by EI and enter the first cell. Odd electron fragment ions are especially troublesome because their recombi-

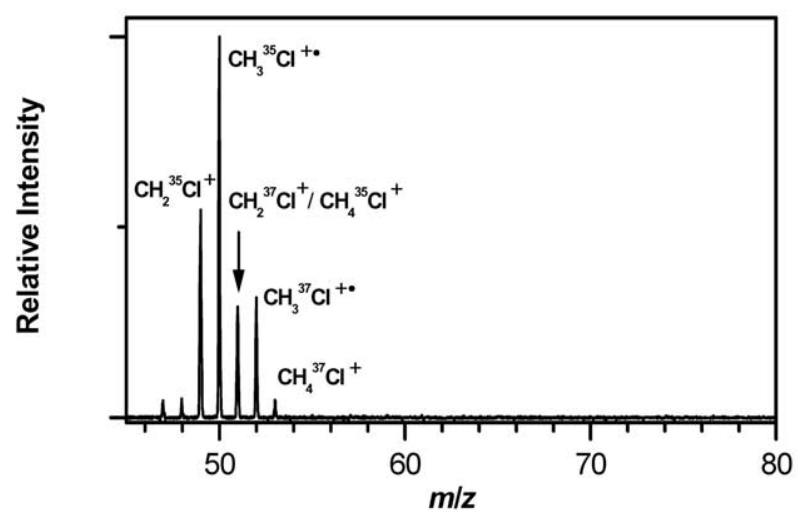

Figure 2. $\mathrm{eV}_{\mathrm{C}}$ double focusing spectrum of trans $-\mathrm{C}_{2} \mathrm{H}_{2} \mathrm{Cl}_{2}{ }^{+}$. generated by $17 \mathrm{eV}$ EI with $\mathrm{CH}_{3} \mathrm{Cl}$ in the first cell. $\mathrm{V}_{\mathrm{S}}$ and $\mathrm{V}_{\mathrm{C}}$ were 4005 and $3939 \mathrm{~V}$, respectively. All the peaks are due to Type III ions.

nation energies can be larger than that of the excited electronic state of the molecular ion being probed. In the $70 \mathrm{eV}$ EI spectra of dichloroethylene isomers, $\mathrm{C}_{2} \mathrm{H}_{2}^{+\cdot}$ and $\mathrm{C}_{2} \mathrm{HCl}^{+*}$ appear prominently and have recombination energies comparable to those of the first excited electronic states of the molecular ions. Lowering the electron energy to $\sim 17 \mathrm{eV}$ eliminated these ions almost entirely and was used throughout the study. $\mathrm{C}_{2} \mathrm{H}_{2} \mathrm{Cl}^{+}$ was the only fragment ion appearing prominently in the $17 \mathrm{eV}$ EI spectra with an intensity of $\sim 5 \%$ relative to those of the molecular ions. Even though the presence of $\mathrm{C}_{2} \mathrm{H}_{2} \mathrm{Cl}^{+}$at this level was not expected to critically affect the present study, further checks were made. The recombination energy of $\mathrm{C}_{2} \mathrm{H}_{2} \mathrm{Cl}^{+}$is not available in the literature. Gaussian 98 G2 calculations [30] estimated the recombination energy as $8.80 \mathrm{eV}$, well below those of the three isomers of dichloroethylene cations in the ground electronic states. We also performed the second cell experiment for $\mathrm{C}_{2} \mathrm{H}_{2} \mathrm{Cl}^{+}$selected by the magnetic sector and confirmed that this ion would not affect our charge exchange experiments for the molecular ions.

\section{Charge Exchange Experiments}

Figure 2 shows the $17 \mathrm{eV}$ EI mass spectrum of trans1,2-dichloroethylene (trans- $\mathrm{C}_{2} \mathrm{H}_{2} \mathrm{Cl}_{2}$ ) recorded under $\mathrm{eV}_{\mathrm{C}}$ double focusing conditions with $\mathrm{CH}_{3} \mathrm{Cl}$ in the first cell. $\mathrm{V}_{\mathrm{S}}$ and $\mathrm{V}_{\mathrm{C}}$ were 4005 and $3939 \mathrm{~V}$, respectively. Hence the translational energy of trans $-\mathrm{C}_{2} \mathrm{H}_{2} \mathrm{Cl}_{2}^{+\cdot}$ inside the cell was $66 \mathrm{eV}$. Type III $\mathrm{CH}_{3} \mathrm{Cl}^{+\cdot}$ ions formed the main peaks in the spectrum. Type III $\mathrm{CH}_{2} \mathrm{Cl}^{+}$and $\mathrm{CH}_{4} \mathrm{Cl}^{+}$also appeared weakly in the spectrum, which might be the products of ion-molecule reactions [31] involving $\mathrm{CH}_{3} \mathrm{Cl}^{+\cdot}$ occurring inside the cell. Since the ionization energy of $\mathrm{CH}_{3} \mathrm{Cl}$ is $11.28 \pm 0.01 \mathrm{eV}$ [32], much larger than the recombination energy of $\sim 9.8 \mathrm{eV}$ for trans- $\mathrm{C}_{2} \mathrm{H}_{2} \mathrm{Cl}_{2}^{+\cdot}$ in the ground electronic state, it can be concluded through the exoergicity rule that some trans $-\mathrm{C}_{2} \mathrm{H}_{2} \mathrm{Cl}_{2}^{+\cdot}$ ions entering the collision cell are in a long-lived excited state(s) which is at $\sim 1.5 \mathrm{eV}$ or higher above the ground state. 
Table 1. Charge exchange gases used, their ionization energies (IE) in $\mathrm{eV}$, and success/failure ${ }^{\mathrm{a}}$ to observe charge exchange signals for some precursor ion/charge exchange gas comginations

\begin{tabular}{lcccc}
\hline & & & \multicolumn{2}{c}{ Precursor ions $\left(\mathrm{C}_{2} \mathrm{H}_{2} \mathrm{C}_{2}{ }^{+\cdot}\right)$} \\
\cline { 3 - 5 } Charge exchange gas & IE $(\mathrm{eV})$ & Ref. & Trans & Cis \\
\hline \hline $1,3-\mathrm{C}_{4} \mathrm{H}_{6}$ & $9.07 \pm 0.02$ & 28 & $\mathrm{O}$ & $\mathrm{O}$ \\
$\mathrm{CS}_{2}$ & $10.07 \pm 0.02$ & 37 & $\mathrm{O}$ & $\mathrm{O}$ \\
$1,1-\mathrm{CH}_{2} \mathrm{CF}_{2}$ & $10.29 \pm 0.01$ & 38 & $\mathrm{O}$ & $\mathrm{O}$ \\
$\mathrm{CH}_{3} \mathrm{Br}$ & $10.5 \pm 0.01$ & 39 & $\mathrm{O}$ & $\mathrm{O}$ \\
$\mathrm{CH}_{3} \mathrm{C} 1$ & $11.28 \pm 0.01$ & 26 & $\mathrm{O}$ & $\mathrm{O}$ \\
$\mathrm{CH}_{3} \mathrm{CC} 1 \mathrm{~F}_{2}$ & $11.98 \pm 0.01$ & 26 & $\mathrm{O}$ & $\mathrm{O}$ \\
$\mathrm{Xe}$ & $12.12 \pm 0.02$ & 29 & $\mathrm{X}$ & $\mathrm{X}$ \\
$\mathrm{CH}_{3} \mathrm{~F}$ & 12.50 & 30 & $\mathrm{X}$ & $\mathrm{X}$ \\
$\mathrm{CHF}_{3}$ & 13.86 & 27 & $\mathrm{X}$ & $\mathrm{X}$ \\
\hline
\end{tabular}

aSuccess and failure indicated by $\mathrm{O}$ and $\mathrm{X}$, respectively.

Similar spectra were recorded with reagent gases with widely different ionization energies as listed in Table 1. Intensities of the reagent gas ions relative to that of the incoming trans- $\mathrm{C}_{2} \mathrm{H}_{2} \mathrm{Cl}_{2}^{+\cdot}$ are plotted as a function of the reagent gas ionization energy in Figure 3a. The reagent ion intensity is substantial for reagent gases such as 1,3-butadiene which have an ionization energy [33] less than the recombination energy of trans $-\mathrm{C}_{2} \mathrm{H}_{2} \mathrm{Cl}_{2}^{+\cdot}$ in the ground state. As the former gets larger than the latter, the reagent ion signal decreases and disappears eventually. The charge exchange signal from $\mathrm{Xe}(\mathrm{IE}=12.12 \pm 0.02 \mathrm{eV})[34]$ was a few percent of those from $\mathrm{CH}_{3} \mathrm{Cl}(\mathrm{IE}=11.28 \pm 0.01 \mathrm{eV})$ or $\mathrm{CH}_{3} \mathrm{CClF}_{2}(\mathrm{IE}=11.98 \pm 0.01 \mathrm{eV})$ [32]. Invoking the exoergicity rule, the data suggest the presence of a long-lived excited state of trans- $\mathrm{C}_{2} \mathrm{H}_{2} \mathrm{Cl}_{2}^{+\cdot}$ with the recombination energy a little below $12.12 \mathrm{eV}$. We also recorded the MIKE spectra by introducing the massselected $\mathrm{C}_{2} \mathrm{H}_{2} \mathrm{Cl}_{2}^{++}$ion beam into the second cell filled with a reagent gas. Figure 4 shows such spectra recorded at two different values of the cell potential for trans $-\mathrm{C}_{2} \mathrm{H}_{2} \mathrm{Cl}_{2}^{+\cdot}$ entering the cell filled with $\mathrm{CH}_{3} \mathrm{Cl}$. The peaks marked by arrows in the spectra appear at the kinetic energy corresponding to the cell potential and must be due to ions from the reagent gas. The presence of these peaks confirms that trans- $\mathrm{C}_{2} \mathrm{H}_{2} \mathrm{Cl}_{2}^{+\cdot}$ is responsible for the charge exchange ionization of $\mathrm{CH}_{3} \mathrm{Cl}$. It takes $\sim 30 \mu$ s for the molecular ion to fly from the ion source to the second cell. This may be taken as the virtual lower limit to the lifetime of the long-lived state involved. The remaining two peaks in each spectrum are due to collision-induced dissociation of the molecular ion to $\mathrm{C}_{2} \mathrm{H}_{2} \mathrm{Cl}^{+}$and $\mathrm{C}_{2} \mathrm{H}_{2}^{+}$.

The $\mathrm{eV}_{\mathrm{C}}$ double focusing spectra recorded for cis$\mathrm{C}_{2} \mathrm{H}_{2} \mathrm{Cl}_{2}^{+\cdot}$ using $\mathrm{CH}_{3} \mathrm{Br}$ and $\mathrm{CH}_{3} \mathrm{CClF}_{2}$ as reagent gases are shown in Figure 5. The cis- $\mathrm{C}_{2} \mathrm{H}_{2} \mathrm{Cl}_{2}^{+\cdot} / \mathrm{CH}_{3} \mathrm{Br}$ charge exchange result is similar to that of trans $-\mathrm{C}_{2} \mathrm{H}_{2} \mathrm{Cl}_{2}^{+} /$ $\mathrm{CH}_{3} \mathrm{Cl}$. For $\mathrm{CH}_{3} \mathrm{CClF}_{2}$ reagent gas, its molecular ion was rather unstable and appeared very weakly. Instead, its stable fragments, $\mathrm{CH}_{3} \mathrm{CF}_{2}^{+}$and $\mathrm{CH}_{2} \mathrm{CF}_{2}^{+}$, appeared prominently in the spectrum. Charge exchange signals from Xe and other reagent gases with higher ionization energy were either very weak or hardly observed, as summarized in Table 1 . The situation was somewhat different for $1,1-\mathrm{C}_{2} \mathrm{H}_{2} \mathrm{Cl}_{2}^{+*}$ (1,1-dichloroethylene cation), which ionized $\mathrm{Xe}(\mathrm{IE}=12.12 \pm 0.02 \mathrm{eV})$ as shown in Figure 6 unlike the above two isomers. The charge
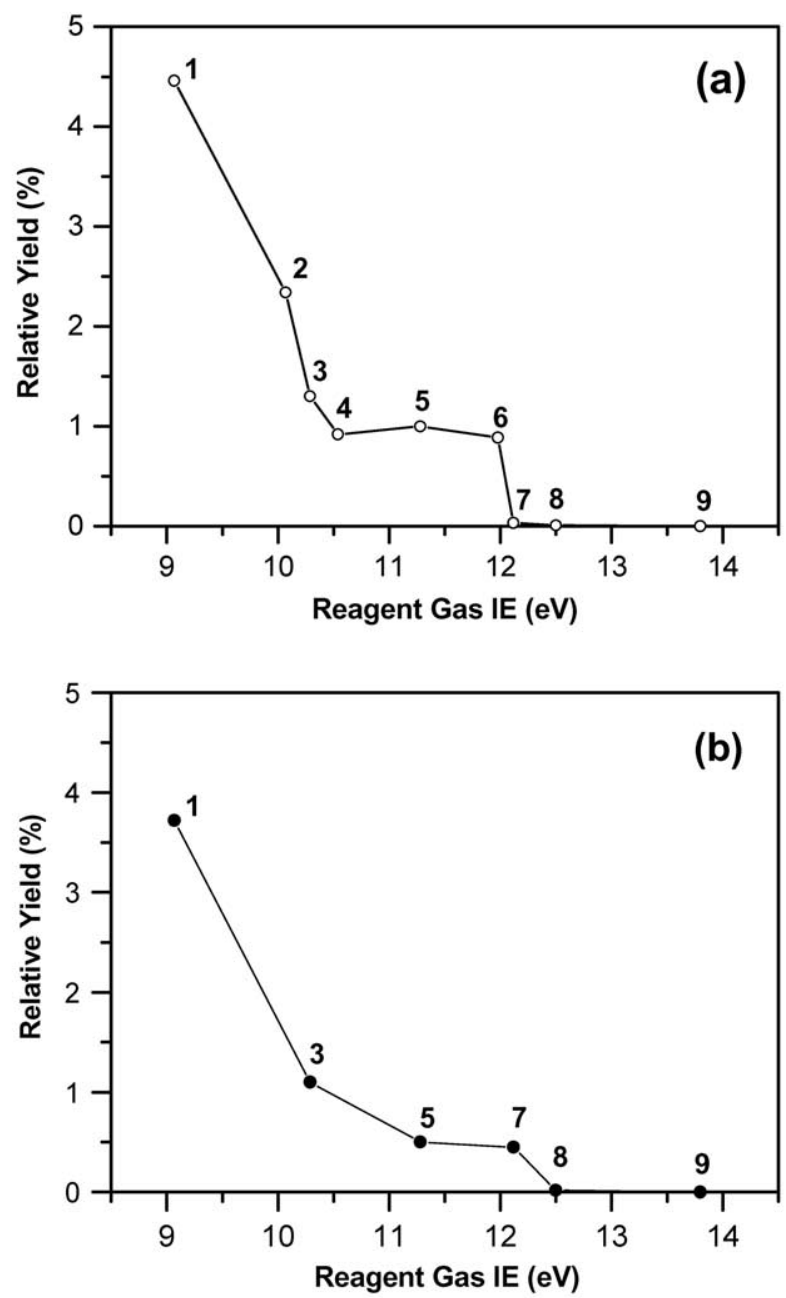

Figure 3. Intensities of the reagent gas ions relative to that of the incoming (a) trans- $\mathrm{C}_{2} \mathrm{H}_{2} \mathrm{Cl}_{2}^{+\cdot}$ and (b) $1,1-\mathrm{C}_{2} \mathrm{H}_{2} \mathrm{Cl}_{2}^{+\cdot}$ plotted as a function of the reagent gas ionization energy. The reagent gases in Table 1 are numbered in order of increasing ionization energy. 


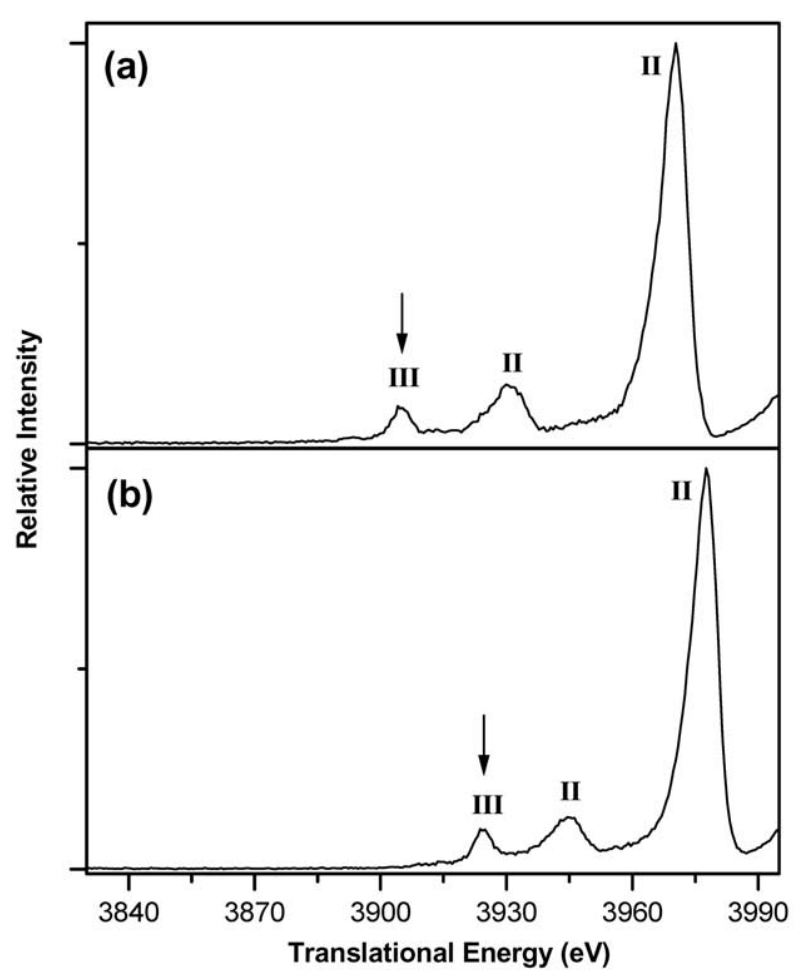

Figure 4. The MIKE spectra recorded with trans $-\mathrm{C}_{2} \mathrm{H}_{2} \mathrm{Cl}_{2}^{+\cdot}$ entering the second cell filled with $\mathrm{CH}_{3} \mathrm{Cl}$. $\mathrm{V}_{\mathrm{S}}$ was $4006 \mathrm{~V}$. $\mathrm{V}_{\mathrm{C}}{ }^{\prime}$ was (a) 3906 and (b) $3925 \mathrm{~V}$. The peaks marked by arrows arise from the reagent gas $\left(\mathrm{CH}_{3} \mathrm{Cl}\right)$. The others are due to collision-induced dissociation of trans- $\mathrm{C}_{2} \mathrm{H}_{2} \mathrm{Cl}_{2}^{+\cdot}$ to $\mathrm{C}_{2} \mathrm{H}_{2} \mathrm{Cl}^{+}$and $\mathrm{C}_{2} \mathrm{H}_{2}^{+\cdot}$.

exchange signal from $\mathrm{CH}_{3} \mathrm{~F}(\mathrm{IE}=12.50 \mathrm{eV})$ [35] with $1,1-\mathrm{C}_{2} \mathrm{H}_{2} \mathrm{Cl}_{2}^{+\cdot}$ was very weak, however. Intensities of the reagent gas ions relative to that of the incoming 1,1$\mathrm{C}_{2} \mathrm{H}_{2} \mathrm{Cl}_{2}^{+\cdot}$ are plotted as a function of the reagent gas ionization energy in Figure 3 to demonstrate the difference from the trans $-\mathrm{C}_{2} \mathrm{H}_{2} \mathrm{Cl}_{2}^{++}$case. Hence it can be concluded that the recombination energy of the longlived excited state of $1,1-\mathrm{C}_{2} \mathrm{H}_{2} \mathrm{Cl}_{2}^{+\cdot}$ is slightly above 12.0 $\mathrm{eV}$ while those of trans- and cis- $\mathrm{C}_{2} \mathrm{H}_{2} \mathrm{Cl}_{2}^{+\cdot}$ are close to or slightly below $12.0 \mathrm{eV}$.

\section{Analysis}

In view of the above experimental results, information on the excited electronic states of the three isomers of dichloroethylene cations up to the recombination energy of $\sim 13 \mathrm{eV}$, or states $\sim 3 \mathrm{eV}$ above the ground state of each isomer, is needed to identify the long-lived excited state(s) observed. Two kinds of electronic states may be present in this range for a molecular cation, namely hole states generated by removal of an electron from an occupied orbital of the neutral and states with an electron in an orbital unoccupied in the neutral. Information on the former states is available from the photoelectron spectrum. The latter states, which may be loosely called LUMO states, can be populated by a two electron process in EI. We calculated the energies of the
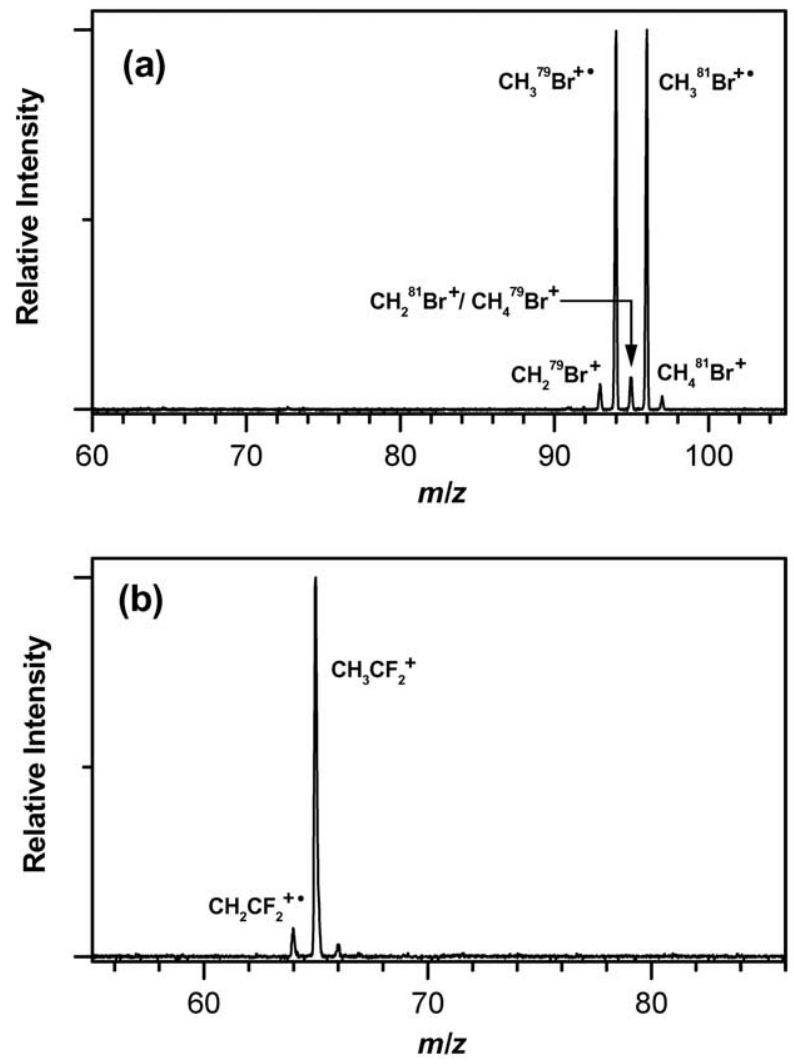

Figure 5. $\quad \mathrm{eV}_{\mathrm{C}}$ double focusing spectra of cis- $\mathrm{C}_{2} \mathrm{H}_{2} \mathrm{Cl}_{2}^{+\cdot}$ generated by $17 \mathrm{eV}$ EI with (a) $\mathrm{CH}_{3} \mathrm{Br}$ and (b) $\mathrm{CH}_{3} \mathrm{CClF}_{2}$ in the first cell. $\mathrm{V}_{\mathrm{S}}$ and $V_{C}$ were 4070 and $4005 \mathrm{~V}$, respectively. All the peaks are due to Type III ions.

lowest lying doublet and quartet LUMO states by the time-dependent density functional theory (TDDFT) at the UB3LYP level using the $6-31 G^{* *}$ basis set. The vertical energies to the doublet states from the ground states were $4.80,4.91$, and $5.39 \mathrm{eV}$ for the trans-, cis-, and $1,1-\mathrm{C}_{2} \mathrm{H}_{2} \mathrm{Cl}_{2}^{+*}$, respectively, while $4.89,5.18$, and $5.07 \mathrm{eV}$, respectively, were obtained for the quartet states. Hence, accepting the TDDFT/B3LYP results that are known to predict the excited state energies rather well, only low-lying hole states appearing in the photoelectron spectra need to be considered to identify the long-lived states observed. Photoelectron spectra of the three isomers of dichloroethylene were reported by several investigators [36-41]. Even though there are some minor differences, excellent agreement in the major aspects among these reports can be seen, such as the vertical ionization energies to the hole states of the cations appearing in the spectra. We will take the spectral data compiled by Kimura and coworkers [36] as the references with some corrections which will be explained later.

Considering only valence molecular orbitals, the electron configuration corresponding to the ground state of the trans $-\mathrm{C}_{2} \mathrm{H}_{2} \mathrm{Cl}_{2}$ neutral is $\left(2 \mathrm{~b}_{\mathrm{g}}\right)^{2}\left(8 \mathrm{~b}_{\mathrm{u}}\right)^{2}\left(10 \mathrm{a}_{\mathrm{g}}\right)^{2}$ $\left(4 \mathrm{a}_{\mathrm{u}}\right)^{2}$ with the orbital designations given by Kimura and coworkers. Here $4 \mathrm{a}_{\mathrm{u}}$ is mostly the $\pi$ orbital of the 

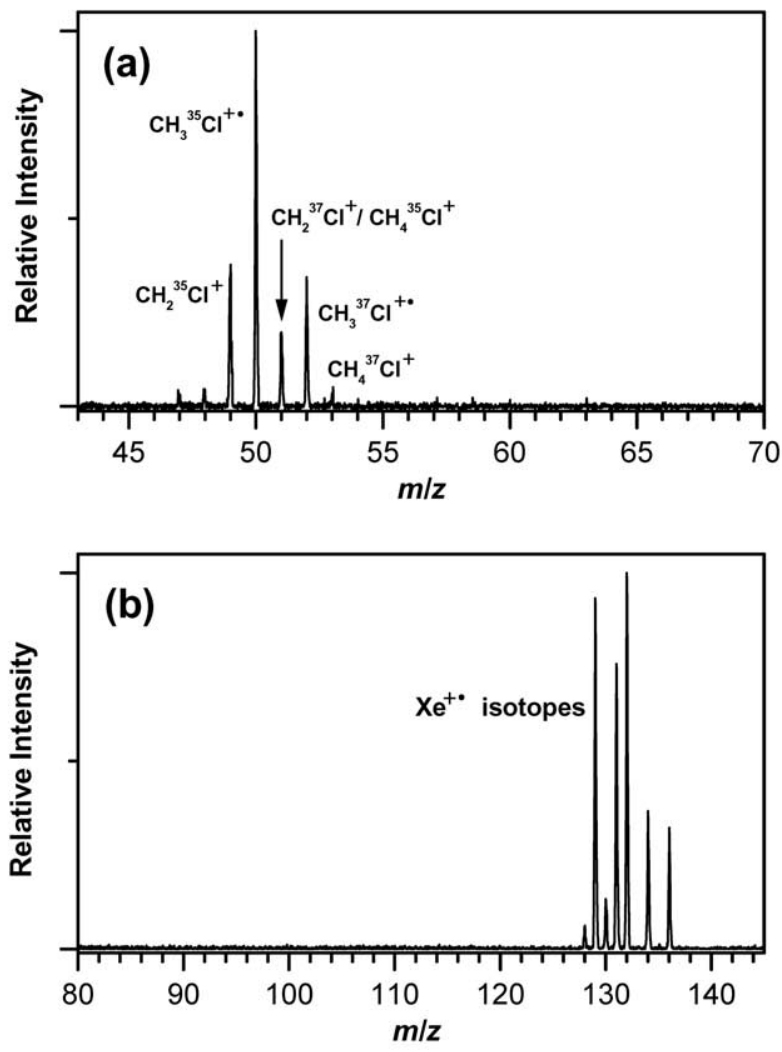

Figure 6. $\quad \mathrm{eV}_{\mathrm{C}}$ double focusing spectra of $1,1-\mathrm{C}_{2} \mathrm{H}_{2} \mathrm{Cl}_{2}^{+\cdot}$ generated by $17 \mathrm{eV}$ EI with (a) $\mathrm{CH}_{3} \mathrm{Cl}$ and (b) Xe in the first cell. $\mathrm{V}_{\mathrm{S}}$ and $\mathrm{V}_{\mathrm{C}}$ were 4070 and $4005 \mathrm{~V}$, respectively. All the peaks are due to Type III ions.

$\mathrm{C}-\mathrm{C}$ bond with some out-of-plane chlorine nonbonding character, or $\pi(\mathrm{C}-\mathrm{C}) / \mathrm{n}\left(\mathrm{Cl}_{3} \mathrm{p}_{\|}\right), 10 \mathrm{a}_{\mathrm{g}}$ and $8 \mathrm{~b}_{\mathrm{u}}$ are mostly the in-plane chlorine nonbonding orbitals, $\mathrm{n}\left(\mathrm{Cl}_{3} \mathrm{p}_{\|}\right)$, and $2 b_{g}$ is mostly $n\left(\mathrm{Cl}_{3} p_{\|}\right)$. Removal of an electron from these orbitals results in the hole states $\tilde{\mathrm{X}}^{2} \mathrm{~A}_{\mathrm{u}}, \tilde{\mathrm{A}}^{2} \mathrm{~A}_{\mathrm{g}}, \tilde{\mathrm{B}}^{2} \mathrm{~B}_{\mathrm{u}}$ and $\tilde{\mathrm{C}}^{2} \mathrm{~B}_{\mathrm{g}}$ which have the vertical ionization energies of $9.81,11.86,11.93$, and $12.61 \mathrm{eV}$, respectively, according to Kimura and coworkers. The ground state electron configuration of the cis isomer is $\left(2 a_{2}\right)^{2}\left(10 a_{1}\right)^{2}\left(9 b_{2}\right)^{2}\left(3 b_{1}\right)^{2}$ with the $3 b_{1}, 9 b_{2}, 10 a_{1}$, and $2 a_{2}$ orbitals having the characters similar to $4 \mathrm{a}_{\mathrm{u}}, 10 \mathrm{a}_{\mathrm{g}}, 8 \mathrm{~b}_{\mathrm{u}}$ and $2 \mathrm{~b}_{\mathrm{g}}$ of the trans isomer, respectively. The hole states for the cis cation are $\tilde{\mathrm{X}}^{2} \mathrm{~B}_{1}, \tilde{\mathrm{A}}^{2} \mathrm{~B}_{2}, \tilde{\mathrm{B}}^{2} \mathrm{~A}_{1}$, and $\tilde{\mathrm{C}}^{2} \mathrm{~A}_{2}$ with the vertical ionization energies of 9.83, 11.85, 12.09, and $12.51 \mathrm{eV}$, respectively. For the 1,1-isomer, Kimura and coworkers found through a Hartree-Fock calculation using the 4-31G basis set that one of the two $n\left(\mathrm{Cl}_{3} \mathrm{p}_{\|}\right)$ orbitals was lower in energy than the $\mathrm{n}\left(\mathrm{Cl} 3 \mathrm{p}_{\|}\right)$orbital which is comparable to $2 b_{g}$ and $2 a_{2}$ in the trans and cis isomers, respectively. This was confirmed by our own calculations at various higher levels suggesting $\left(10 a_{1}\right)^{2}\left(2 a_{2}\right)^{2}\left(8 b_{2}\right)^{2}\left(4 b_{1}\right)^{2}$ as the ground state electron configuration for the 1,1-neutral. The first three excited electronic states appeared vertically at $1.99(\tilde{\mathrm{A}}), 2.57(\tilde{\mathrm{B}})$, and $2.74 \mathrm{eV}(\tilde{\mathrm{C}})$ above the ground state in the TDDFT/ UB3LYP/6-31G** calculation. From the photoelectron peak positions at $10.00,11.67,12.17$, and $12.51 \mathrm{eV}$, the corresponding energy gaps are $1.67,2.17$, and $2.51 \mathrm{eV}$, respectively, in good agreement with the calculated results. The calculated $\widetilde{B}$ and $\tilde{C}$ states had the main characters of $10 a_{1}^{-1}$ and $2 a_{2}^{-1}$, respectively; that is to say, the orbital ordering in 1,1-cation was $2 \mathrm{a}_{2}<10 \mathrm{a}_{1}$ unlike $10 \mathrm{a}_{1}<2 \mathrm{a}_{2}$ in the 1,1-neutral. With the reassignment, the characters of the $\tilde{X}, \tilde{A}, \tilde{B}$, and $\tilde{C}$ states of the 1,1-cation become similar to the corresponding states of the cis and trans cations. Since the calculated excitation energies are slightly different than the experimental data, it will be more appropriate to use the latter values to interpret the charge exchange results. In reference [36], the vertical ionization energies to the whole states are reported, which are either the averages over the vibrational structures of the bands or the peak maxima. In contrast, the recombination energy of the cation in a particular electronic state corresponds to the adiabatic ionization energy to that state. Since the photoelectron peaks for $\tilde{\mathrm{X}}, \tilde{\mathrm{A}}, \tilde{\mathrm{B}}$, and $\tilde{\mathrm{C}}$ in the reference are vibrationally resolved, we estimated their vertical ionization energies from the $0-0$ positions. The results are listed in Table 2 together with the vertical ionization energies mentioned above.

If the $\tilde{\mathrm{C}}$ or higher excited states of trans- and cis-

Table 2. Recombination energies $(\mathrm{eV})^{\mathrm{a}}$ of the $\tilde{\mathrm{X}}, \tilde{\mathrm{A}}, \tilde{\mathrm{B}}$, and $\tilde{\mathrm{C}}$ electronic states of the three isomers of dichloroethylene cations and the calculated radiative lifetimes $(\mu \mathrm{sec})^{\mathrm{b}}$ of the $\tilde{\mathrm{A}}$ and $\tilde{\mathrm{B}}$ states

\begin{tabular}{lcrr}
\hline State & Trans & \multicolumn{1}{c}{ Cis } & 1.1 \\
\hline \hline$\tilde{X}$ & $9.46(9.81)$ & $9.54(9.83)$ & $9.68(10.00)$ \\
$\tilde{A}$ & $11.67(11.86)$ & $11.52(11.85)$ & $11.55(11.67)$ \\
$\tilde{B}$ & $11.85(11.93)$ & $11.86(12.09)$ & $12.13(12.17)$ \\
$\tilde{C}$ & $12.46(12.61)$ & $12.35(12.51)$ & $12.47(12.51)$ \\
\hline Radiative lifetime & Trans & Cis & 1.1 \\
\hline \hline$\tilde{\mathrm{A}} \rightarrow \tilde{X}$ & 180 & $-^{c}$ & $-{ }^{c}$ \\
$\tilde{B} \rightarrow \tilde{X}$ & 4.3 & 220 & 37 \\
$\tilde{B} \rightarrow \tilde{A}$ & $-^{c}$ & 330 & 0.84 \\
\hline
\end{tabular}

${ }^{a}$ Adiabatic ionization energies estimated from the spectral data in ref. 36. Vertical ionization energies tabulated in the same references are shown inside the parentheses.

besults from the TDDFT/UB3LYP/6-31G** calculation.

${ }^{\mathrm{c}}$ Forbidden transitions. 
$\mathrm{C}_{2} \mathrm{H}_{2} \mathrm{Cl}_{2}^{+\cdot}$ are long-lived, $\mathrm{Xe}(\mathrm{IE}=12.12 \pm 0.02 \mathrm{eV})$ can be ionized efficiently by charge exchange with the cations in these states. The fact that the $\mathrm{Xe}^{+\cdot}$ signal was extremely weak suggests that the $\tilde{A}$ and $\tilde{B}$ states are the only candidates for the long-lived excited states in these cases. If only the $\tilde{A}$ states are long-lived which have recombination energies of 11.67 and $11.52 \mathrm{eV}$ for the trans and cis cations, respectively, the prominent appearance of peaks originating from $\mathrm{CH}_{3} \mathrm{CClF}_{2}$ (IE = $11.98 \pm 0.01 \mathrm{eV}$ ) can not be explained. This suggests long lifetimes for the $\tilde{\mathrm{B}}$ states. The reaction energies $(\Delta \mathrm{E})$ evaluated for the charge exchange of the $\tilde{B}$ states with $\mathrm{CH}_{3} \mathrm{CClF}_{2}$ using data in Tables 1 and 2 are 0.13 and 0.12 $\mathrm{eV}$, respectively, for the trans and cis cations, which are slightly larger than the $0.1 \mathrm{eV}$ criterion established previously [24]. The slight mismatch may have been caused either by errors in the estimation of the adiabatic ionization energies of the $\tilde{\mathrm{B}}$ states or by an error in the ionization energy of $\mathrm{CH}_{3} \mathrm{CClF}_{2}$ reported in the literature. In the case of the 1,1-cation, inability to ionize $\mathrm{CH}_{3} \mathrm{~F}(\mathrm{IE}=12.50 \mathrm{eV})$ indicates that the $\tilde{\mathrm{C}}$ or higher states decay or dissociate rapidly. On the other hand, the prominent charge exchange signal from Xe (IE = $12.12 \pm 0.02 \mathrm{eV}$ ) indicates a long lifetime of the $\tilde{B}$ state $(\mathrm{RE}=12.13 \mathrm{eV})$. It is interesting to note that the $\tilde{\mathrm{B}}$ states of the cations of all three isomers are long-lived. These states are generated by removal of an electron from an in-plane nonbonding orbital of chlorine. The Ã states of the cations are formed by removal of an electron from the other in-plane nonbonding orbitals. Whether they would have a long lifetime or not can not be determined by the present charge exchange technique.

The fact that an excited electronic state has a long lifetime means that its decay to lower states, either by radiative or by radiationless process, is rather slow. Theoretical calculation of the radiationless decay, or internal conversion in the present case, is rather difficult. However, radiative lifetimes can be evaluated from the oscillator strengths obtained from a TDDFT/ UB3LYP $/ 6-31 G^{* *}$ calculation. The $\tilde{A} \rightarrow \tilde{X}$ transitions in the cis and 1,1-cations are optically forbidden. Even though the similar transition is optically allowed for the trans cation, the calculated radiative lifetime is as long as $180 \mu \mathrm{s}$; that is to say, based on the radiative lifetime alone, there is a possibility that the Ã state of cations of all three isomers are long-lived. The radiative $\tilde{B} \rightarrow \tilde{X}$ transitions are not efficient either, being dipole forbidden for the trans cations and having the calculated lifetimes of 220 and $37 \mu \mathrm{s}$ for the cis and 1,1-cations, respectively. Since the $\tilde{B} \rightarrow \tilde{A}$ transitions can affect the lifetimes of the $\tilde{B}$ states, we also checked radiative lifetimes for these transitions. These were 4.3, 330, and $0.84 \mu \mathrm{s}$ for the trans, cis, and 1,1-isomers, respectively. The results for the trans and 1,1-isomers are incompatible with the experimental results. These values obtained for the transitions between two excited states can be erroneous, however, especially because minor energy errors for the two close-lying states can lead to large errors in the radiative lifetimes.

\section{Conclusions}

Detection of ions from various reagent gases with different ionization energies by charge exchange has shown that an electronic state(s) lying $\sim 2 \mathrm{eV}$ above the ground states of trans-, cis-, and 1,1- $\mathrm{C}_{2} \mathrm{H}_{2} \mathrm{Cl}_{2}^{+\cdot}$ are longlived when ions are generated by $17 \mathrm{eV}$ EI. There are two electronic states of the cations in this energy range, $\tilde{\mathrm{A}}$ and $\tilde{\mathrm{B}}$, both of which are formed by removal of an electron from the chlorine nonbonding orbitals of the neutrals. Results from the charge exchange with $\mathrm{Xe}$ indicate that the $\tilde{\mathrm{B}}$ states are long-lived. Whether the $\tilde{\mathrm{A}}$ states are also long-lived or not can not be determined by the present experiments. Since the $\tilde{A}$ and $\tilde{B}$ states are very close in energy, there is a possibility that these states interconvert freely. As far as they do not undergo rapid relaxation to the ground states, this model is also compatible with the experimental results. Finding longlived states in cations with mixed halogen substitution will be useful to establish the general validity of the correlation that an ionic state generated by removal of an electron from an in-plane orbital of a neutral can have a very long lifetime.

\section{Acknowledgments}

This work was supported financially by CRI, Ministry of Science and Technology, Republic of Korea. MK thanks the Ministry of Education for the Brain Korea 21 fellowship.

\section{References}

1. McGowan, J. W. The Excited State in Chemical Physics; John Wiley and Sons: New York, 1981, pp 1-492.

2. Klessinger, M.; Michl, J. Excited States and Photochemistry of Organic Molecules; VCH: New York, 1995, pp 1-537.

3. Laane, J.; Takahashi, H.; Bandrauk, A. Structure and Dynamics of Electronic Excited States; Springer-Verlag: Berlin, 1998, pp 1-320.

4. Lever, A. B. P. Excited States and Reactive Intermediates; ACS: Washington, DC, 1986, pp 1-276.

5. Rosenstock, H. M.; Wallenstein, M. B.; Wahrhaftig, A. L.; Eyring, H. Absolute Rate Theory for Isolated Systems and the Mass Spectra of Polyatomic Molecules. Proc. Nat. Acad. Sci. USA 1952, 38, 667-678.

6. Miller, B. E.; Baer, T. Kinetic Energy Release Distribution in the Fragmentation of Energy-Selected Vinyl and Ethyl Bromide Ions. Chem. Phys. 1984, 85, 39-45.

7. Lifshitz, C.; Long, F. A. Some Observations Concerning the Positive Ion Decomposition of $\mathrm{C}_{2} \mathrm{~F}_{6}$ and $\mathrm{C}_{3} \mathrm{~F}_{8}$ in the Mass Spectrometer. J. Phys. Chem. 1965, 69, 3746-3751.

8. Kim, D. Y.; Choe, J. C.; Kim, M. S. Photodissociation Dynamics of the Propargyl Bromide Molecular Ion. J. Chem. Phys. 2000, $113,1714-1724$.

9. Won, D. S.; Kim, M. S.; Choe, J. C.; Ha, T. K. Anisotropic Photodissociation of $\mathrm{CH}_{3} \mathrm{Cl}^{+}$. J. Chem. Phys. 2001, 115, 54545460 .

10. Bombach, R.; Dannacher, J.; Stadelmann, J.-P.; Vogt, J. The Fragmentation of Formaldehyde Molecular Cations: The Lifetime of $\mathrm{CD}_{2} \mathrm{O}^{+}\left(\tilde{\mathrm{A}}^{2} \mathrm{~B}_{1}\right)$. Chem. Phys. Lett. 1981, 77, 399-402.

11. Zhou, X.; Wang, J.; Shukla, A.; Futrell, J. A Tandem Mass Spectrometry Study of the Role of Electronically Excited States in the Collision-Induced Dissociation of the Hexafluoroben- 
zene Molecular Cation. Int. J. Mass Spectrom. 2000, 194, 171179.

12. Biggerstaff, J.; Qian, K.; Howard, S.; Shukla, A.; Futrell, J. Evidence for a Long-Lived Excited State of $\mathrm{CH}_{4}^{+}$from a Beam Scattering Study of the Collision-Induced Dissociation of $\mathrm{CH}_{4}^{+}$ to $\mathrm{CH}_{2}^{+}$at Low Energy. Chem. Phys. Lett. 1988, 151, 507-510.

13. Bondybey, V. E.; English, J. H.; Miller, T. A. Laser Induced Fluorescence Spectrum of Matrix Isolated $\mathrm{CS}_{2}^{+}$. J. Chem. Phys. 1979, 70, 1621-1625.

14. Chawla, R.; Krishnamurthy, M.; Shukla, A. K.; Futrell, J. H. Collision-Induced Dissociation of $\mathrm{CO}_{2}^{+}$Cations: Evidence for a Long-Lived Excited State. Chem. Phys. Lett. 1999, 301, 531-536.

15. Möhlmann, G. R.; Bhutani, K. K.; De Heer, F. J.; Tsurubuchi, S. Lifetimes of the Vibronic $\tilde{\mathrm{A}}^{2} \mathrm{~A}_{1}$ States of $\mathrm{H}_{2} \mathrm{O}^{+}$and of the ${ }^{3} \Pi_{\mathrm{i}}$ $\left(\mathrm{v}^{\prime}=0\right)$ State of $\mathrm{OH}^{+}$. Chem. Phys. 1978, 31, 273-280.

16. Qian, K.; Shukla, A. K.; Futrell, J. Collision-Induced Intramolecular Energy Transfer and Dissociation of Acetone Molecular Ion. J. Chem. Phys. 1990, 92, 5988-5996.

17. Qian, K.; Shukla, A. K.; Futrell, J. Observation of Isolated Electronic States in the Collision-Induced Dissociation of Nitromethane Ions. Rapid Commun. Mass Spectrom. 1990, 4, 222224.

18. Qian, K.; Shukla, A. K.; Futrell, J. Collision-Induced Dissociation Dynamics of the Acetone Cation: Intraconversion of Translational and Electronic Energy. Chem. Phys. Lett. 1990, 175, 51-54.

19. Fenistein, S.; Futrell, J.; Heninger, M.; Marx, R.; Yang, Y. M. On the Lifetime of Electronically Excited Acetone Molecular Ions. Chem. Phys. Lett. 1991, 179, 125-130.

20. Qian, K.; Shukla, A. K.; Futrell, J. Electronic Excitation in Low-Energy Collisions: A Study of the Collision-Induced Dissociation of Nitromethane Ion by Crossed-Beam Tandem Mass Spectrometry. J. Am. Chem. Soc. 1991, 113, 7121-7129.

21. Chawla, R.; Shukla, A. K.; Futrell, J. Collision-Induced Dissociation of Low Energy Benzene Ions. Int. J. Mass. Spectrom. Ion Processes 1997, 165/166, 237-247.

22. Kim, M. S.; Kwon, C. H.; Choe, J. C. Discovery of Benzene Cation in a Very Long-Lived Excited Electronic State. J. Chem. Phys. 2000, 113, 9532-9539.

23. Kwon, C. H.; Kim, M. S.; Choe, J. C. Charge Exchange Ionization in Collision Cells as a Method to Detect the Presence of Long-Lived Excited Electronic States of Polyatomic Ions. J. Am. Soc. Mass Spectrom. 2001, 12, 1120-1126.

24. Youn, Y. Y.; Choe, J. C.; Kim, M. S. Reliability of Estimation of Recombination Energies of Molecular Radical Cations by Charge Exchange and a Test of the Exoergicity Rule. Rapid Commun. Mass Spectrom. 2003, 17, 314-319.

25. Youn, Y. Y.; Kwon, C. H.; Choe, J. C.; Kim, M. S. Discovery of Long-Lived Excited Electronic States of Chlorobenzene, Bromobenzene, Benzonitrile, and Phenyl Acetylene Cations. J. Chem. Phys. 2002, 117, 2538-2545.

26. Youn, Y. Y.; Choe, J. C.; Kim, M. S. Discovery of Long-Lived Excited Electronic States of Vinylchloride, Vinylbromide, Vinyliodide, and Acrylonitrile Cations. J. Am. Soc. Mass. Spectrom. 2003, 14, 110-116.
27. Kim, M. S. Fragmentation Probability in Collisional-Activation Mass Spectrometry (CA/MS). I. Effects of Sequential Collisional Excitation. Int. J. Mass Spectrom. Ion Phys. 1983, 50, 189-203.

28. Kim, Y. H.; Kim, M. S. Analysis of a Mass-Analyzed Ion Kinetic Energy Peak Profile for a Metastable Ion Decomposition Occurring in a Collision Cell Floated at High Voltage. Rapid Commun. Mass Spectrom. 1991, 5, 25-29.

29. Cooks, R. G.; Beynon, J. H.; Caprioli, R. M.; Lester, G. R. Metastable Ions; Elsevier: Amsterdam, 1973; p 44.

30. Frisch, M. J.; Trucks, G. W; Schlegel, H. B; Scuseria, G. E; Robb, N. A; Cheeseman, J. R; Zakrzewski, V. G; Montgomery, J. A., Jr.; Stratmann, R. E; Burant, J. C; Dapprich, S; Millam, J. M; Daniels, A. D; Kudin, K. N; Strain, M. C; Farkas, O; Tomasi, J; Barone, V; Cossi, M; Cammi, R; Mennucci, B; Pomelli, C; Adamo, C; Clifford, S; Ochterski, J; Petersson, G. A; Ayala, P. Y; Cui, Q; Morokuma, K; Malick, D. K; Rabuck, A. D; Raghavachari, K; Foresman, J. B; Cioslowski, J; Ortiz, J. V; Stefanov, B. B; Liu, G; Liashenko, A; Piskorz, P; Komaromi, I; Gomperts, R; Martin, R. L; Fox, D. J; Keith, T; Al-Laham, M. A; Peng, C. Y; Nanayakkara, A; Wong, M. W; Andres, J. L; Gonzalez, C; Head-Gordon, M; Replogle, E. S; Pople, J. A. Gaussian 98, Revision A.6.; Gaussian, Inc.: Pittsburgh, PA, 1998.

31. Herod, A. A.; Harrison, A. G.; McAskill, N. A. Ion-Molecule Reactions in Methyl Fluoride and Methyl Chloride. Can. J. Chem. 1971, 22, 2217-2222.

32. Watanabe, K.; Nakayama, T.; Mottl, J. Ionization Potentials of Some Molecules. J. Quant. Spectrom. Rad. Trans. 1962, 2, 369 382.

33. Parr, A. C.; Elder, F. A. Photoionization of 1,3-Butadiene, 1,2-Butadiene, Allene, and Propyne. J. Chem. Phys. 1968, 49, 2659-2664.

34. Rauh, E. G.; Ackermann, R. J. The First Ionization Potentials of the Transition Metals. J. Chem. Phys. 1979, 70, 1004-1007.

35. Krauss, M.; Walker, J. A.; Dibeler, V. H. Mass Spectrometric Study of Photoionization. X. Hydrogen Chloride and Methyl Halides. J. Res. NBS 1968, 72A, 281.

36. Kimura, K.; Katsumata, S.; Achiba, Y.; Yamazaki, T.; Iwata, S. Handbook of HeI Photoelectron Spectra of Fundamental Organic Molecules; Japan Scientific Societies Press: Tokyo, 1981, pp 100-102.

37. Wittel, K.; Bock, H. Chlor- und Bromäthylene-Beispiele Für Änderungen in $\pi$ - und $\sigma$-Systemen. Chem. Ber. 1974, 107 317-338.

38. Bock, H; Wittel, K. Photoelectron Spectra and Molecular Properties of trans-Dihalogenoethylenes: Substituent Effects Spin-Orbit Coupling. J. C. S. Chem. Comm. 1972, 602-603.

39. Von Niessen, W.; Asbrink, L.; Bieri, G. 30.4 nm He(II) Photoelectron Spectra of Organic Molecules Part VI. HalogenoCompounds $(\mathrm{C}, \mathrm{H}, \mathrm{X} ; \mathrm{X}=\mathrm{Cl}, \mathrm{Br}, \mathrm{I})^{+}$. J. Electron. Spectroscop. Relat. Phenom. 1982, 26, 173-201.

40. Jonathan, N.; Ross, K.; Tomlinson, V. The Photoelectron Spectra of Dichloroethylenes. Int. J. Mass Spectrom. Ion Phys. 1970, 4, 51-58.

41. Lake, R. F.; Thompson, S. H. Photoelectron Spectra of Halogenated Ethylenes. Proc. Roy. Soc. Lond. A. 1970, 315, 323-338. 